\title{
CRESCIMENTO E PRODUTIVIDADE DO MAMOEIRO FERTIRRIGADO COM FÓSFORO POR GOTEJAMENTO SUPERFICIAL E SUBSUPERFICIAL ${ }^{1}$
}

\author{
ELVES DE ALMEIDA SOUZA², EUGÊNIO FERREIRA COELHO ${ }^{3}$, VITAL PEDRO DA SILVA PAZ4, \\ MAURÍCIO ANTÔNIO COELHO FILHO ${ }^{5}$
}

\begin{abstract}
RESUMO - O presente trabalho teve como objetivo determinar o efeito da freqüência de aplicação de fósforo via água de irrigação por gotejamento superficial e subsuperficial no crescimento e na produtividade do mamoeiro (Carica papaya L.), do grupo Formosa, cultivar Tainung $\mathrm{n}^{\circ} 1$. As variáveis de crescimento avaliadas foram: índice de área foliar, altura da planta e diâmetro do caule, mediante amostragens aos 39; 69; 182 e 317 dias após o plantio (DAP). O experimento seguiu um delineamento em blocos casualizados, num esquema fatorial 2 x $4+1$, com três repetições e doze plantas por parcela. Foram avaliados dois sistemas de microirrigação (gotejamento subsuperficial e superficial) e quatro freqüências de fertirrigação com fósforo (30; 60; 90 e 120 dias) via água de irrigação, utilizando como fonte o fosfato monoamônico (MAP), mais um tratamento com adubação convencional via sólida, utilizando o superfosfato simples. As análises de variância indicaram que houve efeito significativo do sistema de irrigação aos 317 DAP na variável de crescimento altura da planta e efeito da interação sistema x freqüência de fertirrigação no diâmetro do caule aos 69 DAP e índice de área foliar aos 182 DAP. O fósforo, quando aplicado via fertirrigação nas freqüências de 30 e 60 dias, nos sistemas superficial e subsuperficial, proporcionou melhores resultados nas variáveis de crescimento e na produtividade. Em todas as variáveis de crescimento analisadas, bem como na produtividade, os tratamentos fertirrigados foram, em média, superiores ao tratamento com adubação convencional.
\end{abstract}

Termos para indexação: Carica papaya, freqüência de aplicação, fosfato monoamônico.

\section{GROWTH AND YIELD OF PAPAYA FERTIRRIGATED WITH PHOSPHOROUS BY SURFACE AND SUBSURFACE DRIP}

\begin{abstract}
The objective of the work was to determine the effect of frequency of phosphorous application by surface and subsurface drip water irrigation on papaya, cv, Tainung $\mathrm{n}^{\mathrm{o}} 1$ (Carica papaya L.) and yield. The evaluated growth variable was: days after planting (DAP). The experiment followed a random block design in a factorial $2 \times 4+1$, with three replications and 12 plants per plot. Two micro irrigation systems (subsurface drip irrigation and surface drip irrigation) and four phosphorous fertirrigation frequencies (30, 60, 90 e 120 days) plus a conventional application were considered. Monoammonic phosphate (MAP) was used as phosphorous source. Variance analysis indicated that there was effect of the irrrigation system ggrowth variables for 317 DAP. Also the analysis indicated significant effect of the interaction irrigation system $\mathrm{x}$ fertirrigation frequency on steam diameter for 69 DAP and for leaf area index for 182 DAP. The phosphorous application by fertirrigation at frequencies of 30 and 60 days in both drip systems provided better results on growth variables and on yield. All growth variables and yield from fertirrigated treatments were larger than the ones obtained under conventional fertilizing.
\end{abstract}

Index terms: Carica papaya, frequency of application, monoamonic phosphite.

\section{INTRODUÇÃO}

A irrigação localizada reúne as condições tecnológicas capazes de impulsionar o crescimento da fruticultura, pois permite a aplicação de pequenas quantidades de água em alta freqüência diretamente na zona radicular, mantendo a umidade do solo próxima do limite superior de disponibilidade de água (Nir, 1982; Dasberg \& Bresler, 1985). Entre os sistemas do método de irrigação localizada, destaca-se o gotejamento, que vem sendo usado para a cultura do mamoeiro, propiciando melhores condições de desenvolvimento e produção quando comparado aos sistemas de irrigação por sulco e aspersão (Rungsimanop et al., 1988). De acordo com Papa (1984), não houve diferença significativa entre esse sistema e a microaspersão. Porém, em condições do Recôncavo Baiano, Coelho et al. (2002) verificaram que a microaspersão proporcionou uma produtividade $10 \%$ superior ao sistema de gotejamento. A irrigação por gotejamento possui as melhores condições de proporcionar alto controle e alta uniformidade na aplicação de água e fertilizantes. A alta uniformidade, próxima de $90 \%$, proporciona maior eficiência da fertirrigação, sendo considerada, atualmente, como um dos mais importantes fatores de produtividade para a agricultura. E tem sido citada como o método mais racional para a otimização da adubação (López 1998). A possibilidade de parcelamento na aplicação dos fertilizantes é fundamental para o aproveitamento balanceado dos nutrientes, conforme as necessidades das plantas (Dasberg \& Bresler, 1985). Com relação à aplicação de fósforo via fertirrigação, por ser um nutriente que apresenta baixa mobilidade no solo e possui alta capacidade de adsorção, seu parcelamento pode não produzir os mesmos resultados verificados para outros nutrientes, como o potássio e o nitrogênio (Costa et al., 1986). A sua aplicação via fertirrigação por gotejamento, principalmente subsuperficial, pode aumentar o movimento do nutriente no solo em 5 a 10 vezes se comparado à aplicação via sólida pelo método convencional (Rauschkolb et al., 1976). Rolston et al. (1986) comentaram que o fósforo aplicado via fertirrigação pode atingir até $0,20 \mathrm{~m}$ de raio em relação ao gotejador. Segundo Papadopoulos (2001), a alta freqüência de aplicação de fósforo via água de irrigação pode favorecer o aumento substancial da concentração desse nutriente, disponibilizando-o à planta por um maior tempo. Bar-Yosef et al. (1989) afirmaram que a aplicação de fósforo via irrigação por gotejamento subsuperficial apresentou diferença significativa na redistribuição do fertilizante no perfil do solo, comparado com a irrigação por gotejamento superficial. Estudos realizados por Coelho et al. (2002), avaliando os efeitos dos diferentes sistemas de microirrigação nas variáveis biométricas de plantas de mamão (altura da planta, área foliar e diâmetro do caule) e produtividade do pomar, mostraram que a área foliar e a produtividade em sistema de gotejamento superficial foram $33 \%$ e $27 \%$ superiores ao sistema de gotejamento subsuperficial na linha, respectivamente. Para as demais variáveis, os valores observados foram próximos nos dois sistemas. O objetivo deste trabalho foi avaliar o crescimento vegetativo e a produtividade do mamoeiro, sob diferentes freqüências de aplicação de fósforo, via água de irrigação por gotejamento superficial e subsuperficial.

\footnotetext{
${ }^{1}$ (Trabalho 118/2004). Recebido: 07/10/2004. Aceito para publicação: 17/11/2005.

${ }^{2}$ Engenheiro Agrônomo, mestrando em Ciências Agrárias da UFBA, Cruz das Almas-BA. CEP 44.380-000. E-mail: elvis.agro@bol.com.br, Tel.: (75) 621-5727.

${ }^{3}$ Embrapa Mandioca e Fruticultura Tropical, Cruz das Almas-BA, C.P. 07, CEP 44.380-000. E-mail: ecoelho@cnpmf.embrapa.br.

${ }^{4}$ Departamento de Engenharia Agrícola da Escola de Agronomia da UFBA, Cruz das Almas-BA, CEP 44.380-000. E-mail: vpspaz@ufba.br.

${ }_{5}^{5}$ Bolsista do CNPq, Embrapa Mandioca e Fruticultura Tropical, Cruz das Almas-BA, C.P. 07, CEP 44.380-000.
} 
TABELA 1 - Descrição dos tratamentos estudados na cultura do mamoeiro Tainung $\mathrm{n}^{\circ} 1$, em função do sistema de irrigação e freqüências de aplicação de fósforo, estudados na cultura do mamoeiro. Cruz das Almas-BA, 2002.

\begin{tabular}{ccc}
\hline Tratamentos & Sistema & Freqüência de fertirrigação (dias) \\
\hline T1 & Manual & Supersimples - Plantio e cobertura \\
T2 & Gotejamento superficial & MAP - freqüência de 30 dias \\
T3 & Gotejamento superficial & MAP - freqüência de 60 dias \\
T4 & Gotejamento superficial & MAP - freqüência de 90 dias \\
T5 & Gotejamento superficial & MAP - freqüência de 120 dias \\
T6 & Gotejamento subsuperficial & MAP - freqüência de 30 dias \\
T7 & Gotejamento subsuperficial & MAP - freqüência de 60 dias \\
T8 & Gotejamento subsuperficial & MAP - freqüência de 90 dias \\
T9 & Gotejamento subsuperficial & MAP - freqüência de 120 dias \\
\hline
\end{tabular}

\section{MATERIAL E MÉTODOS}

O trabalho foi desenvolvido na área experimental da Embrapa Mandioca e Fruticultura, localizada no município de Cruz das Almas BA ( $\left.12^{\circ} 48^{\prime} \mathrm{S} ; 39^{\circ} 06^{\prime} \mathrm{W} ; 225 \mathrm{~m}\right)$. O clima da região é classificado como úmido a subúmido, pluviosidade média anual de $1.143 \mathrm{~mm}$ (D'Angiolella et al., 1998). O solo da área experimental é classificado como Latossolo Amarelo distrófico típico, textura argilosa a moderada, ácido, com declividade entre 10 e $15 \%$, apresentando horizontes subsuperficiais coesos, sendo bastante profundo, bem intemperizado, oriundo de sedimentos da formação Capim Grosso de baixa fertilidade química. Apresenta as seguintes características físicas: areia total $444 \mathrm{~g} \mathrm{~kg}^{-1}$; silte $131 \mathrm{~g} \mathrm{~kg}^{-1}$; argila $425 \mathrm{~g} \mathrm{~kg}^{-1}$, e densidade do solo de $1,36 \mathrm{~kg} \mathrm{dm}^{-3}$ (Souza \& Souza, 2001). O experimento foi conduzido em um pomar com o mamoeiro (Carica papaya $\mathrm{L}$.), cultivar Tainung $\mathrm{n}^{\circ} 1$, do grupo Formosa, instalado em dezembro de 2002, no espaçamento 3,5 x 1,5 m, irrigado por gotejamento superficial e subsuperficial com dois gotejadores por planta instalados a $0,30 \mathrm{~m}$ da planta. No sistema superficial, com gotejadores, a vazão foi de $3,75 \mathrm{~L} \mathrm{~h}^{-1} \mathrm{e}$, no subsuperficial, a vazão foi de $2 \mathrm{~L} \mathrm{~h}^{-1}$ com o emissor a $0,25 \mathrm{~m}$ de profundidade. $\mathrm{O}$ delineamento experimental foi em blocos casualizados, com três repetições e doze plantas por parcela, em esquema fatorial 2 x $4+1$, sendo dois métodos de fertirrigação, quatro freqüências de aplicação e o tratamento convencional (testemunha). Todos os tratamentos receberam $120 \mathrm{~kg}$ de $\mathrm{P}_{2} \mathrm{O}_{5}$ ha $^{-1}$ por ano, sendo $40 \mathrm{~kg}$ no plantio e $80 \mathrm{~kg}$ em cobertura. Os tratamentos consistiram da aplicação convencional com o superfosfato simples no plantio e em cobertura, no $6^{\circ}$ mês após o plantio, e os fertirrigados superficial e subsuperficial utilizaram como fonte o fosfato monoamônico (MAP), nas freqüências de 30; 60; 90 e 120 dias (Tabela 1).

Além do fósforo, todos os tratamentos receberam nitrogênio e potássio via fertirrigação a cada sete dias, nas dosagens de $350 \mathrm{~kg}$ ha ${ }^{1}$ ano $^{-1}$ de cada nutriente, conforme recomendação de Oliveira et al. (2002). A fertirrigação foi realizada com uso de uma bomba injetora hidráulica. As variáveis de crescimento: índice de área foliar, altura da planta e diâmetro do caule foram avaliadas aos 39; 69; 182 e 317 dias após o plantio (DAP). Para a determinação do índice de área foliar, foi necessária a determinação da área foliar da planta, pelo seguinte modelo (Alves \& Santos, 2002):
$\mathrm{AF}=0,0947 \cdot \mathrm{L}^{2,7352}$

sendo, AF - Área foliar, $\mathrm{m}^{2}$; L- Comprimento do lóbulo central, $\mathrm{m}$. O índice de área foliar (IAF) foi obtido pela relação:

$\mathrm{IAF}=\frac{\mathrm{AF}}{\mathrm{As}}$

sendo, IAF - Índice de área foliar; As - Área de cada planta $\left(\mathrm{m}^{2}\right)$.

A altura da planta e o diâmetro do caule foram medidos a 0,20 $\mathrm{m}$ da superfície do solo. Foram realizadas análises de variância dos dados biométricos acima, em cada coleta, até os 317 dias após o plantio (DAP).

As colheitas foram feitas a partir do oitavo mês do plantio, numa freqüência de, pelo menos, 15 dias até o $16^{\circ}$ mês. Os frutos colhidos foram separados em três classes: classe 0 - frutos de peso inferior a $1 \mathrm{~kg}$; classe 1 - frutos de peso entre 1 e $2 \mathrm{~kg}$, e classe 2 - frutos de peso superior a $2 \mathrm{~kg}$.

\section{RESULTADOS E DISCUSSÃO}

A análise de variância indicou efeito significativo aos 317 DAP para o sistema de irrigação para a variável de crescimento altura da planta, e aos 69 DAP da interação sistema x freqüência de fertirrigação no diâmetro do caule para e aos 182 DAP para o índice de área foliar (Tabela 2). A altura da planta foi a variável com menores diferenças entre os tratamentos, em valores absolutos, seja no sistema superficial, seja no sistema subsuperficial (Figura 1). Este comportamento foi traduzido na análise de variância, ocorrendo diferenças significativas entre os sistemas aos 317 DAP, sendo que o sistema superficial foi, em média, $11 \%$ superior ao sistema subsuperficial (Tabela 3). Os diâmetros do caule do mamoeiro para o sistema superficial e subsuperficial estão representados na Figura 2. Aos 39 DAP, o diâmetro médio do caule no sistema superficial de 0,10 foi $18 \%$ superior ao subsuperficial e $27 \%$ superior ao tratamento com adubação convencional (T1); sendo o diâmetro do caule uma variável sensível ao déficit hídrico (Bernardo, 1996), estes resultados podem ser atribuídos às diferenças do teor de umidade na superfície do solo entre os dois sistemas, conforme Souza

TABELA 2 - Análise de variância da altura da planta aos 317 dias após o plantio, do diâmetro do caule aos 69 DAP e do índice de área foliar aos 182 DAP.

\begin{tabular}{|c|c|c|c|c|c|c|c|}
\hline \multirow[t]{2}{*}{ Fonte de variação } & \multirow[t]{2}{*}{ G.L. } & \multicolumn{2}{|c|}{ Diâmetro do caule } & \multicolumn{2}{|c|}{ Índice de área foliar } & \multicolumn{2}{|c|}{ Altura da planta } \\
\hline & & QM & $\mathrm{Pr}>\mathrm{Fc}$ & $\mathrm{QM}$ & $\operatorname{Pr}>\mathrm{Fc}$ & QM & $\mathrm{Pr}>\mathrm{Fc}$ \\
\hline Bloco & 2 & 0,00026 & 0,010 & 0,562 & 0,1750 & 0,255 & 0,0184 \\
\hline Sistema de irrigação & 1 & 0,00001 & 0,550 & 0,329 & 0,3017 & 0,293 & $0,0268 *$ \\
\hline Freqüência de fertirrigação & 3 & 0,00008 & 0,160 & 0,279 & 0,4331 & 0,005 & 0,9571 \\
\hline Sistema $\mathrm{x}$ freqüência & 3 & 0,00013 & $0,049 *$ & 0,100 & $0,0415^{*}$ & 0,139 & 0,0714 \\
\hline Fatorial x T1 & 1 & 0,00010 & 0,130 & 0,579 & 0,1758 & 0,000 & 0,9015 \\
\hline Erro & 16 & 0,00040 & & 0,288 & & 0,049 & \\
\hline Total corrigido & 26 & & & & & & \\
\hline $\mathrm{CV}(\%)$ & & $12,34 \%$ & & $42,17 \%$ & & $10,1 \%$ & \\
\hline
\end{tabular}

*significativo a $5 \%$ de probabilidade, pelo teste $\mathrm{F}$. 

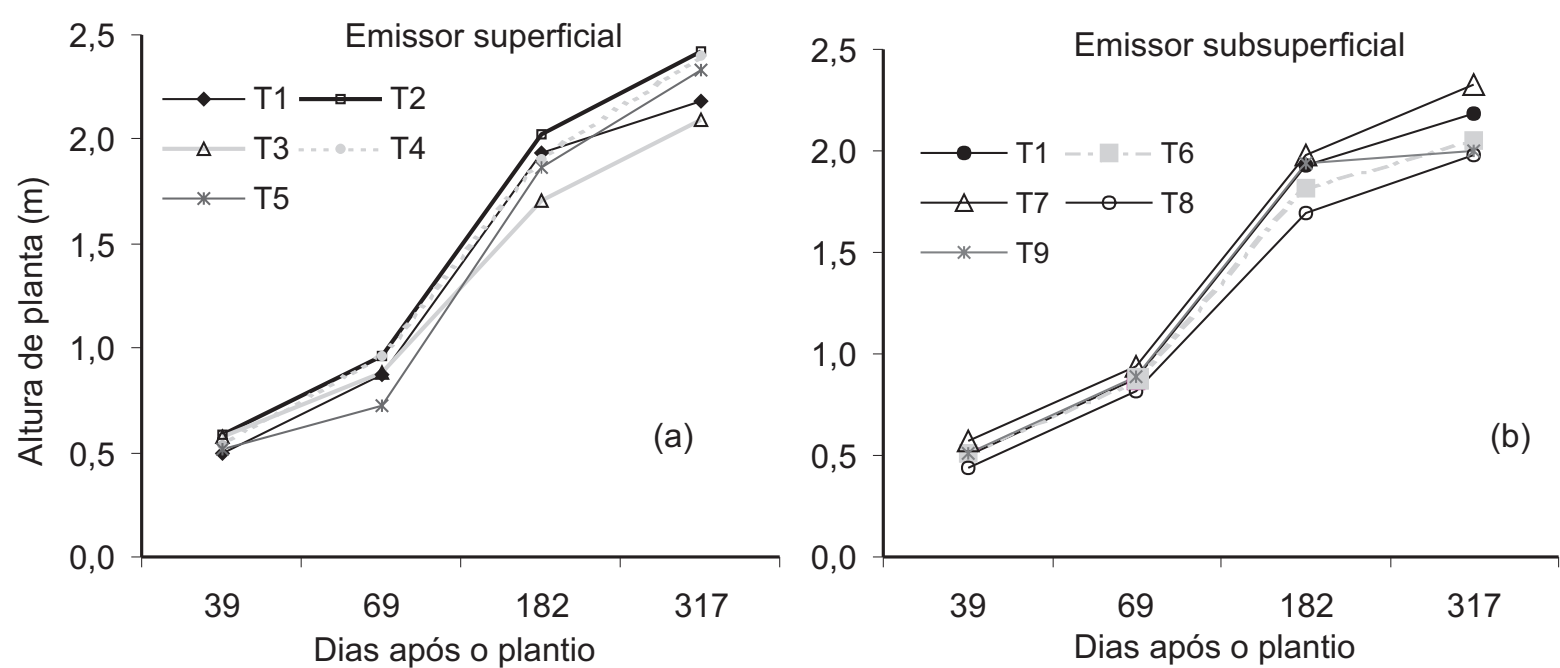

FIGURA 1 - Altura da planta para (a) sistema superficial e (b) sistema subsuperficial, sob diferentes freqüências de aplicação de fósforo (média de três repetições).

TABELA 3 - Desdobramento para as variáveis altura da planta aos 317 DAP, diâmetro do caule aos 69 DAP e índice de área foliar aos 182 DAP, em função do sistema de irrigação e da freqüência de fertirrigação.

\begin{tabular}{lccccc}
\hline Sistema & Trat. & Freqüência (dias) & Altura da planta $(\mathrm{m})$ & Diâmetro do caule (m) & Índice de área foliar \\
\hline Adubação convencional & T1 & & 2,18 & 0,047 & 0,86 \\
\hline Gotejamento superficial & T2 & 30 & 2,42 & $0,054^{\text {ab }}$ & $1,58^{\mathrm{a}}$ \\
Gotejamento superficial & T3 & 60 & 2,09 & $0,056^{\text {ab }}$ & $0,90^{\mathrm{a}}$ \\
Gotejamento superficial & T4 & 90 & 2,40 & $0,060^{\mathrm{a}}$ & $1,34^{\mathrm{a}}$ \\
Gotejamento superficial & T5 & 120 & 2,33 & $0,043^{\mathrm{b}}$ & $1,01^{\mathrm{a}}$ \\
\hline Media & & & $2,31^{\mathrm{a}}$ & 0,050 & 1,21 \\
\hline Gotejamento subsuperficial & T6 & 30 & 2,05 & $0,050^{\mathrm{a}}$ & $1,17^{\mathrm{a}}$ \\
Gotejamento subsuperficial & T7 & 60 & 2,33 & $0,057^{\mathrm{a}}$ & $2,30^{\mathrm{a}}$ \\
Gotejamento subsuperficial & T8 & 90 & 1,98 & $0,048^{\mathrm{a}}$ & $1,11^{\mathrm{a}}$ \\
Gotejamento subsuperficial & T9 & 120 & 2,00 & $0,052^{\mathrm{a}}$ & $1,19^{\mathrm{a}}$ \\
\hline Media & & $2,09^{\mathrm{b}}$ & 0,052 & 1,44
\end{tabular}

Médias seguidas pela mesma letra nas colunas não diferem entre si pelo teste de Tukey a $5 \%$ de probabilidade.

et al. (2003), que encontraram diferenças de umidade na superfície do solo entre o sistema subsuperficial e o superficial. Para o sistema superficial, ocorreram diferenças significativas entre os diâmetros do caule para as freqüências de aplicação de fósforo, não sendo observado para o subsuperficial; o tratamento T4 (freqüência de 90 dias) obteve maior média entre os demais, porém apresentou diferenças significativas para os tratamentos T2 (30 dias) e T3 (60 dias), diferindo apenas do tratamento T5 (120 dias) (Tabela 3). No entanto, verifica-se diferença entre os tratamentos T4 e T5. Comparando-se os sistemas fertirrigados com o tratamento manual (T1), verificou-se que este apresentou resultados do diâmetro do caule inferiores aos demais, salvo para o tratamento T5, justificado pela menor freqüência de fertirrigação, ou seja, 120 dias (Tabela 3).

Analisando os sistemas de irrigação aos 182 DAP (Figura 2), os tratamentos T7 e T2 apresentaram os maiores valores absolutos de diâmetro do caule, sendo $18 \%$ e $28 \%$, respectivamente, superiores em valores absolutos ao tratamento T1; aos $317 \mathrm{DAP}$, os mesmos tratamentos apresentaram resultados semelhantes, porém $22 \%$ e $27 \%$ superiores ao tratamento T1 (testemunha). Das variáveis estudadas, o índice de área foliar (IAF) foi o que apresentou maior variação em valores absolutos, acentuando-se, principalmente, aos 182 DAP (Figura 3). Observou-se, também, que os valores absolutos de IAF nos tratamentos fertirrigados foram superiores aos obtidos no tratamento com adubação convencional. Comparando o IAF nos dois sistemas de irrigação pela
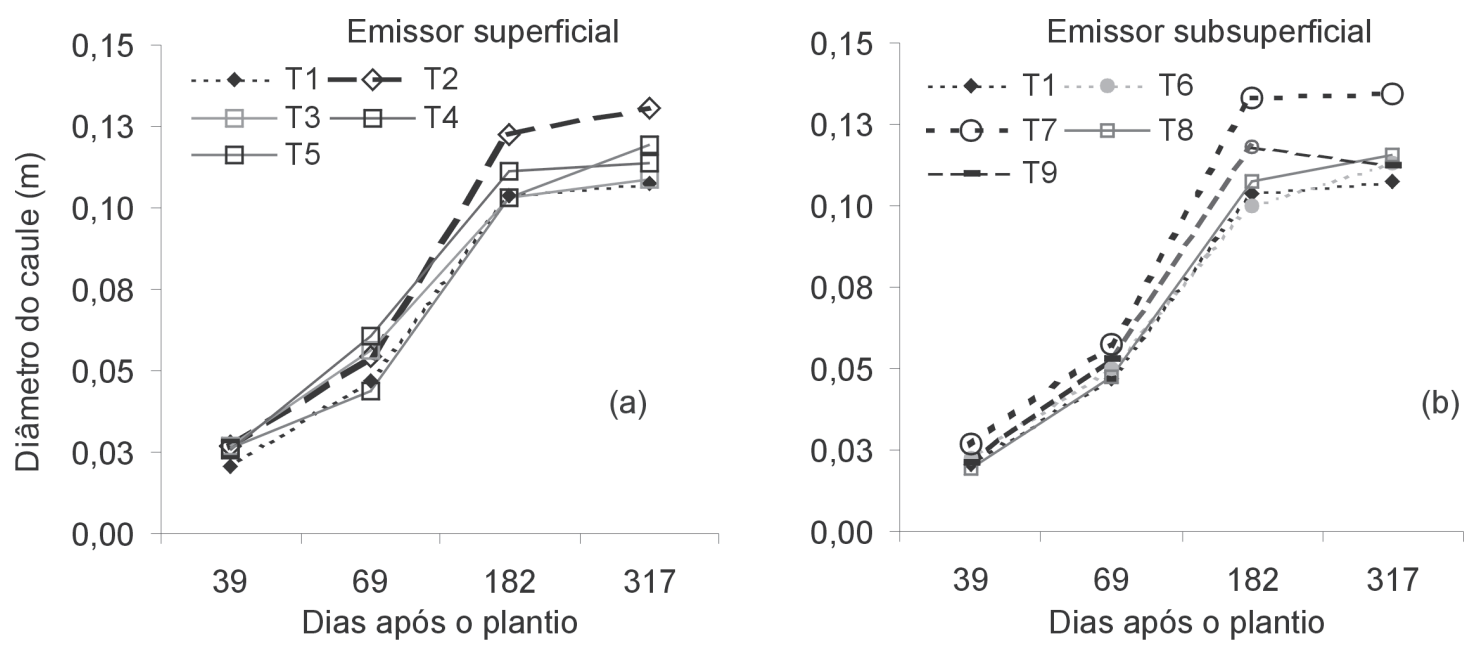

FIGURA 2 - Diâmetro do caule para (a) sistema superficial e (b) subsuperficial, sob diferentes freqüências de aplicação de fósforo (média de três repetições). 

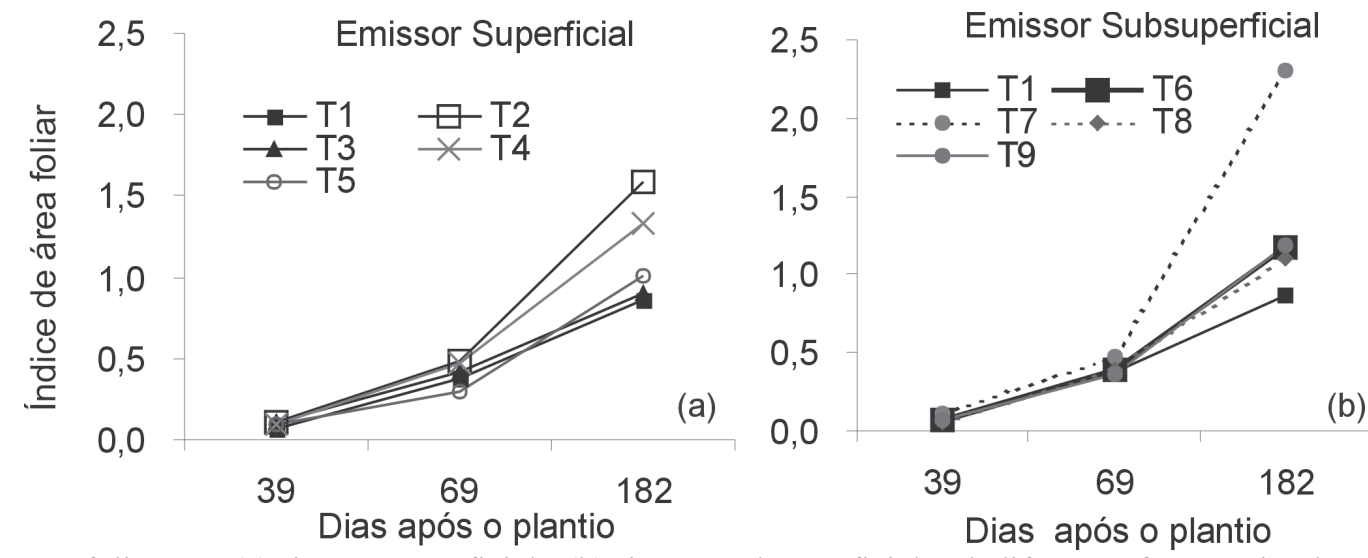

FIGURA 3 - Índice de área foliar para (a) sistema superficial e (b) sistema subsuperficial, sob diferentes freqüências de aplicação de fósforo (média de três repetições).

média do período estudado (39; 69 e 182 DAP), o sistema subsuperficial foi $11,5 \%$ superior, em valores absolutos, ao superficial. O IAF dos dois sistemas de irrigação, aos $39 \mathrm{DAP}$, apresentou valor médio para o sistema superficial $29 \%$ superior, em valores absolutos, à média do sistema subsuperficial, e $65 \%$ superior ao convencional (T1). Nesse período, os tratamentos T2, T3 e T7 apresentaram valores semelhantes de IAF, porém superiores aos demais (Figura 3 ).

Os valores médios de IAF, aos 69 DAP, foram semelhantes para os dois sistemas, sendo que, em média, os sistemas superficial e subsuperficial foram $12 \%$ e $9 \%$ superiores, em valores absolutos, ao tratamento convencional (T1), respectivamente. Nesse período, os maiores valores do índice de área foliar, de 0,48 e 0,47 foram obtidos nos tratamentos $\mathrm{T} 2$ e $\mathrm{T} 7$, sendo $28 \%$ e $26 \%$ superiores em valores absolutos ao tratamento T1 (testemunha), com 0,37. Apesar da interação sistema de irrigação x freqüência para o índice de área foliar (Tabela 2), não ocorreram diferenças significativas entre os tratamentos (Tabela 3 ). Considerando os valores absolutos obtidos nos dois sistemas, os resultados foram semelhantes aos 39 e 69 DAP, para os tratamentos T7 e T2, porém superiores aos demais (Figura 3), com destaque para o sistema subsuperficial (T7), com um IAF de 2,3 , que foi $46 \%$ e $168 \%$ superior em valores absolutos a T2 e T1, respectivamente 1,58 e 0,86.

Em geral, as variáveis de crescimento do mamoeiro fertirrigado com fósforo apresentaram melhores resultados com a freqüência de aplicação de 30 dias para o sistema superficial e 60 no sistema subsuperficial. Os resultados obtidos para o IAF até 182 DAP diferiram dos resultados encontrados por Coelho et al. (2002), com uma área foliar do sistema de gotejamento superficial 33\% superior ao sistema de gotejamento subsuperficial. Nas demais variáveis, altura da planta e diâmetro do caule, os valores observados foram próximos entre os sistemas de microirrigação.

A análise de variância não mostrou efeito do sistema de irrigação ou dos tratamentos de freqüências de aplicação do fósforo na produtividade $(\mathrm{P}>0,05)$ do mamoeiro; entretanto, em valores absolutos, as maiores produtividades ocorreram para a freqüência de aplicação de 60 dias para o gotejamento enterrado $\left(75,2 \mathrm{tha}^{-1}\right)$, seguido da freqüência de 30 dias para o gotejamento superficial $\left(67,5 \mathrm{tha}^{-1}\right)$, conforme a Figura 4. A aplicação convencional e o tratamento de freqüência de aplicação de 90 dias em gotejamento enterrado foram os tratamentos de menores produtividades ( 48,8 e $39,5 \mathrm{tha}^{-1}$, respectivamente). Os demais tratamentos resultaram em produtividades muito próximas entre si, com valores próximos de $56 \mathrm{t} \mathrm{ha}^{-1}$. Os resultados de produtividade são condizentes com os de crescimento das plantas até os 317 DAP, em que apenas a variável altura de planta apresentou diferença significativa entre as médias dos tratamentos. Em todos os tratamentos, a produtividade de frutos de peso entre $1 \mathrm{~kg}$ e $2 \mathrm{~kg}$ correspondeu a $70 \%$ da produtividade total. A classe de pesos inferiores a $1 \mathrm{~kg}$ ficou entre $15 \%$ e $23 \%$ da produtividade total para todos os tratamentos. Estes resultados, tomados a partir de valores absolutos, indicaram não ter havido efeito dos tratamentos nas classes de peso dos frutos, conforme observado na análise de variância.

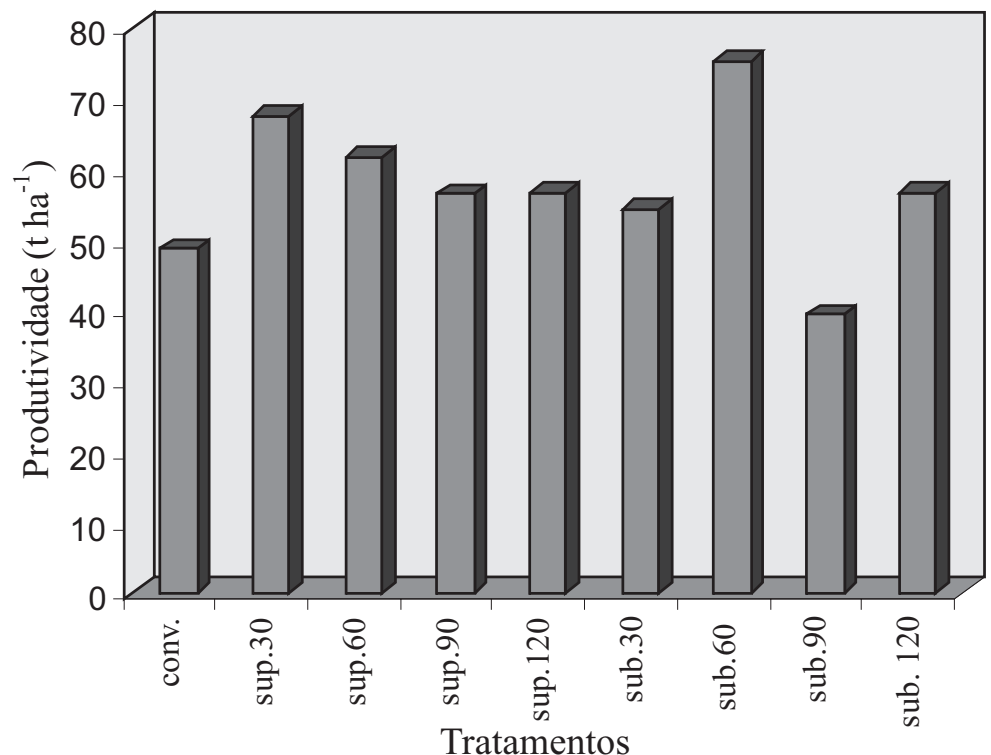

FIGURA 4 - Produtividade do mamoeiro sob diferentes freqüências de aplicação de fósforo via água de irrigação.

\section{CONCLUSÕES}

1.0 fósforo, quando aplicado via fertirrigação nas freqüências de 30 e 60 dias, nos sistemas superficial e subsuperficial, respectivamente, favoreceu o crescimento da planta de mamoeiro.

2. A altura de plantas apresentou menor variação entre os sistemas e freqüências de aplicação de fósforo.

3. Não houve efeito da freqüência de aplicação do fósforo via água de irrigação na produtividade do mamoeiro cv. Tainung número 1.

\section{REFERÊNCIAS}

ALVES, A.A.C.; SANTOS, E.L. Estimativa da área foliar do mamoeiro: método não destrutivo. In: CONGRESSO BRASILEIRO DE FRUTICULTURA, 17., 2002, Belém. Anais... CD ROM.

BAR-YOSEF, B.; SAGIN, B.; MARKOVITVH, T. Sweet corn response to surface and subsurface trickle phosphorus fertigation. Agronomy Journal, Madison, v. 81, p.443-447. 1989.

BERNARDO, S.; CARVALHO, J. A.; SOUSA, E. F. Irrigação do mamoeiro. Campos dos Goytacazes: 1996. v.1.20p. (Boletim Técnico, 5).

COELHO, E. F.; LIMA, D. M.; QUEIRÓZ, J. S. Desenvolvimento e produção do mamoeiro irrigado por diferentes sistemas de irrigação In. CONGRESSO NACIONAL DE IRRIGAÇÃO E DRENAGEM, 12., 2002, Uberlândia Anais... v.1, CD ROM,

COSTA, E. E. da; FRANÇA, G. E. de; ALVES, V. M. C. Aplicação de fertilizantes via água de irrigação. Informe Agropecuário, Belo Horizonte, v.12, n.139, p.63-68, 1986. 
D’ANGiOlella, G. L. B.; CASTRO NETO, M. T.; COELHO, E. F. Tendências Climáticas para os Tabuleiros Costeiros da Região de Cruz das Almas In: CONGRESSO BASILEIRO DE ENGENHARIA AGRÍCOLA, 27., 1998, Poços de Caldas. Anais... v.1, p. 43-45.

DASBERG, S.; BRESLER. E. Drip irrigation manual. Logan: International Irrigation Center, 1985.95p.

LÓPEZ, C.C. (Coord.). Fertirrigacion cultivos horticolas y ornamentales. Barcelona: Mundi-Prensa, 1998.475p.

NIR, D. Drip irrigation. In: FINKEL, H.J. CRC handbook of irrigation technology. Boca Raton: CRC Press. 1982. v.1, p. 247-298.

OLIVEIRA, A.M.G. Mamão. In: BORGES, A.L; COELHO, E.F; TRINDADE, A.V. (Org.). Fertirrigações em fruteiras tropicais. Cruz das Almas: EMBRAPA-MANDIOCA E FRUTICULTURA, 2002, 138.

PAPA, E.G. Produção e qualidade de frutos de mamoeiro (Carica papaya L.) cultivado em casa de vegetação e em campo com irrigação por gotejamento ou jato pulsante. 1984. 39f. Dissertação (Mestrado)Faculdade de Ciências Agrárias e Veterinárias, Universidade Estadual Paulista, Jaboticabal, 1984.

PAPADOPOULOS, I. Fertirrigação: situação atual e perspectivas para o futuro. In: FOLEGATTI. M.V. et al. (Coord.) Fertirrigação flores frutas e hortaliças. Guaíba: Agropecuária, 2001. p.331.

RAUSCHKOLB, R.S.; ROLSTON, D.E.; MILLER, R.J.; CARLTON,A.B.; BURAU, R.J. Phosphorus fertilization with drip irrigation. Soil Science Society America Journal, Madison, v.40. p.68-71, 1976.

ROLSTON, D.E.; MILLER, R.J.; SCHULBACH, H. Management principles ln: NAKAYAMA, F.S.; BUCKS, D.A. Trickle irrigation for crop prodution. Amsterdam: Elsevier, 1986.p.317-345.

RUNGSIMANOP, C.; SUKSRI, A.; SRINUKUL, S. Some irrigation methods which influence the growth of custard apple and papaya when intercropped in northeast Thailand. Horticultural Abstract. Farnham Royal, v. 58. p.472-478, 1988.

SOUZA, L. da S.; SOUZA, L.D. Caracterização físico-hídrica de solos da área do Centro Nacional de Pesquisa de Mandioca e Fruticultura Tropical. Cruz das Almas. Bahia: EMBRAPA-CNPMF, 2001. 56p. (Boletim de Pesquisa, 20).

SOUZA, E.A.; COELHO, E.F; PAZ, V.P. Da; SILVA, T.S.M. Distribuição da umidade no perfil do solo em irrigação por gotejamento superficial e subsuperficial num latossolo, usando a TDR. In: CONIRD, 14., 2003, Juazeiro. Anais... CD-ROM. 